\title{
Patient ignorance is the main reason for treatment delay in primary rhegmatogenous retinal detachment in The Netherlands
}

F Goezinne', EC La Heij', TTJM Berendschot', NG Tahzib', LS Koetsier', JGMM Hoevenaars', ATA Liem ${ }^{1}$, A Kijlstra ${ }^{1,2}$, CAB Webers ${ }^{1}$ and F Hendrikse ${ }^{1}$

\begin{abstract}
Aims Treatment delay of progressive visionthreatening conditions should be minimal. In this study, the treatment delay of patients with a rhegmatogenous retinal detachment (RRD) undergoing retinal detachment surgery was quantified, and causes for this delay were evaluated.

Materials and methods Consecutive patients $(n=205)$ presenting with a primary RRD between June 2006 and June 2007 at the tertiary referral center (TRC) were interviewed. Five categories of delay were discerned in the following: 'patient delay,' 'general practitioner's delay,' 'referring ophthalmologist's delay,' 'delay at the TRC' and 'delay before surgery at the TRC'. In addition, overall delay was calculated. Results In total, 186 eyes were included in the analysis. Median overall delay between the patients' first symptoms and RRD surgery was 10 days. Almost $60 \%$ of this overall delay time was due to patient delay and the delay of the general practitioner. More than $50 \%$ of patients had a delay owing to unawareness of the symptoms. The median patient delay was significantly lower in patients with a vitreous hemorrhage and in patients with a history of a RRD in the fellow eye. Conclusions The major reason for patient delay with a RDD was the patients' unawareness and unfamiliarity with the symptoms of a retinal detachment.
\end{abstract}

Eye (2009) 23, 1393-1399; doi:10.1038/eye.2008.272; published online 12 September 2008;

Keywords: delay; interview; primary rhegmatogenous retinal detachment; referral

\section{Introduction}

A rhegmatogenous retinal detachment (RRD) is caused by a retinal break with subsequent shift of intraocular fluid and liquefied vitreous into the subretinal space. This causes a separation of the neuroretina from the retinal pigment epithelium. ${ }^{1}$ If untreated, most RRD will progress to a complete detachment and subsequently result in vision loss of the affected eye. ${ }^{1}$ The annual incidence of RRD is about 10 per 100000 persons. ${ }^{2,3}$ The following predictors were found to be risk factors for functional and anatomic success after primary RRD repair: more than 6 days of visual loss, ${ }^{4}$ macular involvement and the size of detachment area. ${ }^{3-9}$ As all these factors are dependent on the time interval between the first symptoms noted by the patient and the timing of surgery, we decided to investigate the reasons for treatment delay.

\section{Patients and methods}

In this prospective study, we included all consecutive cases with a primary RRD who visited the Department of Ophthalmology of the Academic Hospital Maastricht between June 2006 and June 2007. This department functions as a tertiary referral center (TRC), especially for retinal detachment cases. Excluded were all patients with a secondary retinal detachment. The study was performed with the agreement of the institutional ethics committee. Patients were informed about the study procedure and provided informed consent.

The study was conducted in accordance with the ethical standards laid down in the 1964 Declaration of Helsinki Principles.
${ }^{1}$ The Department of Ophthalmology, University Hospital Maastricht, Maastricht, Limburg, The Netherlands

${ }^{2}$ The Animal Sciences Group, Wageningen University and Research Center, Lelystad, The Netherlands

Correspondence:

F Goezinne,

Department of Ophthalmology, University Hospital Maastricht,

P.O. Box 5800,

P. Debyelaan 25, $6202 \mathrm{AZ}$,

Maastricht,

The Netherlands

Tel: + 3143 3875346;

Fax: + 31433875343 .

E-mail: fgo@

soog.azm.nl

Received: 18 February 2008 Accepted in revised form: 7 August 2008 Published online: 12

September 2008

Presented at ARVO Fort Lauderdale, 2008 
The following preoperative clinical characteristics of the study patients were collected: age, sex, preoperative visual acuity, myopia (defined as spherical equivalent of -6 diopters or more), prior intraocular surgery (ie, cataract and retinal detachment of the fellow eye), the number of detached quadrants of the retina, whether or not the central area of the macula (foveal region) was involved in the detachment, which was measured by an optical computer tomography and the number of days this region was involved. We defined this as the subjective duration of the sudden drop in visual acuity and/or decreased visual field. We further noted the presence of proliferative vitreoretinopathy, graded according to the classification of RRD, ${ }^{10}$ the type and localization of the retinal tear, the number of breaks, the presence of a vitreous hemorrhage and the type of surgery (scleral buckling or vitrectomy).

Preoperatively, the patients were interviewed by one of the three co-authors (FG, JH and LSK) using a questionnaire (see Table 1), and when necessary, questions were clarified. Patients were requested to carefully estimate the time interval in days for the delay they had experienced. We helped the patient to relate this to a happening that they could refer to, such as a birthday. This method assisted in defining the delay time more precisely, at least up to a few days, even if the event occurred more than 2 months before. When the answers yielded no clear answers, or patients were uncertain, these cases were excluded. Five different categories of delay were discerned: 'patient delay,' 'general practitioner's (GP) delay,' 'referring ophthalmologist's (RO) delay,' 'delay at the TRC' and 'delay before surgery at the TRC'. In addition, the overall (meaning cumulative) delay was calculated per patient (see Table 2). Information on three of the five categories was obtained by questioning the patient (patient delay, GP delay and RO delay). 'The delay at the TRC' was determined using admission papers. The exact date of the surgery was noted from the surgery report. An example for one patient is shown in Figure 1. By interviewing the patients, we noted that they had no knowledge or experience with the symptoms of posterior vitreous detachment (PVD) and/or retinal detachment. For instance, they explained the interviewer that they did not think that the symptoms of flashes, floaters or visual field reduction were serious, so they did not haste to visit a physician.

Statistical analysis was performed after the consultation of a statistician, and using the SPSS software 13.0. The days of delay were converted to a logarithmic scale to create an equal distribution. After this conversion, statistical analysis was performed using a independent sample $t$-test (significance was defined as $P<0.05)$.

\section{Results}

A total of 206 eyes from 205 patients with an RRD (134 males and 71 females, respectively, 65.5 and 34.5\%) were included in this study. No reliable answers were obtained in 7 out of 205 patients. In two out of these seven patients, the RRD was coincidentally found, and these patients were therefore not able to report on the start of their symptoms. In five other patients, the results of the interviews were unreliable owing to dementia or confusion. Another 12 patients were excluded who had a primary symptomatic PVD without retinal defects and/or patients with a retinal break who underwent photocoagulation, without an RRD at the initial visit and who later developed an RRD. These 19 patients were excluded, making a total of 186 eyes that were included in the analysis. The male $v$ f female pseudophakic ratio was $51: 18(3: 1)$. The mean patient age was 59 years (range: 18-87). Ninety-nine eyes were right eyes (53.2\%) and 87 eyes were left eyes (46.8\%). Clinical characteristics of all 186 patients are summarized in Table 3 . Fifteen fellow eyes ( $8.1 \%$ ) had a previous RRD, 33 eyes (17.9\%) were myopic. Scleral buckling surgery was performed in 138 eyes $(74.2 \%)$, whereas a primary pars plana vitrectomy was performed in 48 eyes $(25.8 \%)$ (see Table 3).

The first symptoms experienced by the patients were flashes $(n=70 ; 37.6 \%)$, floaters $(n=112 ; 60.2 \%)$, visual field defects $(n=145 ; 78.8 \%)$ and visual loss $(n=131 ; 70.4 \%)$. The median patient delay of patients complaining of flashes, floaters, visual field defects and sudden visual loss was $6(\mathrm{SD} \pm 27), 15(\mathrm{SD} \pm 41)$, $5(\mathrm{SD} \pm 15)$ and 5 days (SD \pm 16$)$, respectively.

The median overall delay for all 186 eyes was 10 days $(\mathrm{SD} \pm 35)$. The calculation of the mean overall delay time in percentages was $51 \%$ (SD \pm 32 ); it was $9 \%$ for GP delay $(\mathrm{SD} \pm 21)$ and $9 \%$ for the RO delay (SD \pm 20$)$. The delay at the TRC was 5\% (SD \pm 15$)$ and before surgery it was $26 \%$ (SD \pm 25 ). Almost $60 \%$ of this overall delay time was due to patient delay and GP delay. The median patient delay was 4 days ( $\mathrm{SD} \pm 24.5 ; n=186)$ and the median GP delay was 0 days (SD $\pm 20.0 ; n=119)$. The median $\mathrm{RO}$ delay was 0 days $(\mathrm{SD} \pm 20.2 ; n=127)$ and the median delay at the TRC was 0 days (SD $\pm 4.2 ; n=186)$. The median delay before surgery was 1 day $(\mathrm{SD} \pm 4.2$; $n=186$ ) (Table 4). In 104 patients (55.9\%), we found that patient delay was due to unawareness and/or unfamiliarity with the RRD symptoms. In this subgroup of 104 patients, the median patient delay was 6 days $(\mathrm{SD} \pm 31)$. Other reasons for the delay involving the GP, RO and TRC are presented in Table 4.

The median patient delay was longer in patients with a detached macula than in patients without macular detachment; 4 days (SD \pm 30$)$ vs 4 days (SD \pm 14 ), 
Table 1 Questionnaire

Did you experience any flashes? Yes/No
Did you experience any floaters? Yes/No
Did you experience any visual field loss? Yes/No
Did you experience an acute visual loss? Yes/No
For how long? ...........days
For how long? ...........days
For how long?...........days
For how long? ...........days

Patient related delay........... days

When did you first contact the general practitioner/ophthalmologist?

.......................... days ago

Reason for delay:

$$
\text { days ago }
$$

When did the general practitioner/ophthalmologist refer you (at what

General practitioners delay. ...days time did he or she

contact the physician)? $\ldots \ldots \ldots \ldots \ldots \ldots \ldots \ldots$ days ago

Reason for delay:

When did the ophthalmologist refer you to our hospital (at what time Referring ophthalmologist delay. ...days did he or she contact the Academic Hospital Maastricht (AHM))? days ago

Reason for delay:

When did the retinal surgeon at the Academic Hospital Maastricht (AHM) decide to operate (ask retinal surgeon)?

......................... days ago

Reason for delay:

Our out patient clinic delay.............days

At what date did the surgery take place? (this information was collected from the admission papers)

......................... days ago

Reason for delay:

Delay before surgery..........days

Total delay...... days

To fill in after ophthalmologic examination by ophthalmologist or retinal surgeon

Visual acuity....

Funduscopic examination: PVR A/PVR B/PVR C

Foveal involvement Yes/No? (how long)..................................days

Amount of breaks............/horse shoe/hole/oral dialysis/giant retinal tear

Ophthalmologic history;...

Pseudophakia? Yes/No

Fellow eye retinal detachment Yes/No

Myopia? Yes/No dioptres: SE.........

Note: all questions were asked by the same three residents (FG, JH, LK).

although this finding was not statistically significant $(P=0.67)$. Patients with a history of a retinal detachment in the fellow eye $(n=15)$ presented significantly earlier. The median patient delay here was 1.0 days $(\mathrm{SD} \pm 8.0$ ), whereas in patients without a history of retinal detachment $(n=171)$ patient delay was 4 days ( $\mathrm{SD} \pm 25)$, $(P=0.015)$. Moreover, the median patient delay in patients with a vitreous hemorrhage $(n=7)$ was significantly lower than in patients without a vitreous hemorrhage $(P=0.032)$; 1 day (SD \pm 1$)$ vs 4 days $(\mathrm{SD} \pm 25)$. This difference was only found for the category patient delay, but not for the other four delay categories (see Table 5). For myopia, affected eye (right or left), age and symptoms, no statistically significant differences in delay were found.

Nine patients suffered a delay owing to an incorrect diagnosis at the RO, where the RRD had been overlooked. In one case, our center decided to initially undertake alternative interventions (see Table 4), which was defined as an ultrasonography. In one patient, delay was probably due to a misunderstanding between the patient and a desk employee. 
Table 2 Definitions used in this study to specify the different categories of delay

\begin{tabular}{|c|c|}
\hline Categories of delay & Defined as number of days... from ... until... \\
\hline Patient delay & $\begin{array}{l}\text { From the first symptoms (flashes/floaters/visual acuity loss and/or visual field loss) noted by the } \\
\text { patient until the moment the patient made his or her first appointment for this complaint with } \\
\text { either the GP, the RO or the TRC }\end{array}$ \\
\hline GP delay & $\begin{array}{l}\text { From the first moment the patient contacted }{ }^{a} \text { the GP until the moment the GP contacted }{ }^{a} \text { either the } \\
\text { RO or the TRC }\end{array}$ \\
\hline RO delay & $\begin{array}{l}\text { From the first moment the patient or the GP contacted }{ }^{a} \text { the } \mathrm{RO} \text { until the moment the RO referred } \\
\text { the patient }\end{array}$ \\
\hline Delay at the TRC & $\begin{array}{l}\text { From the first moment the patient, GP or RO contacted }{ }^{\mathrm{a}} \text { the department until the patient was } \\
\text { scheduled for surgery }\end{array}$ \\
\hline Delay before surgery at TRC & From the patient was scheduled for surgery until the actual intervention \\
\hline Overall delay & From the first symptoms noted by the patient until the actual intervention \\
\hline
\end{tabular}

$\mathrm{GP}=$ general practitioner; $\mathrm{RO}=$ referring ophthalmologist; $\mathrm{TRC}=$ tertiary referral center.

${ }^{\mathrm{a} C}$ Contacted indicates call or visit.

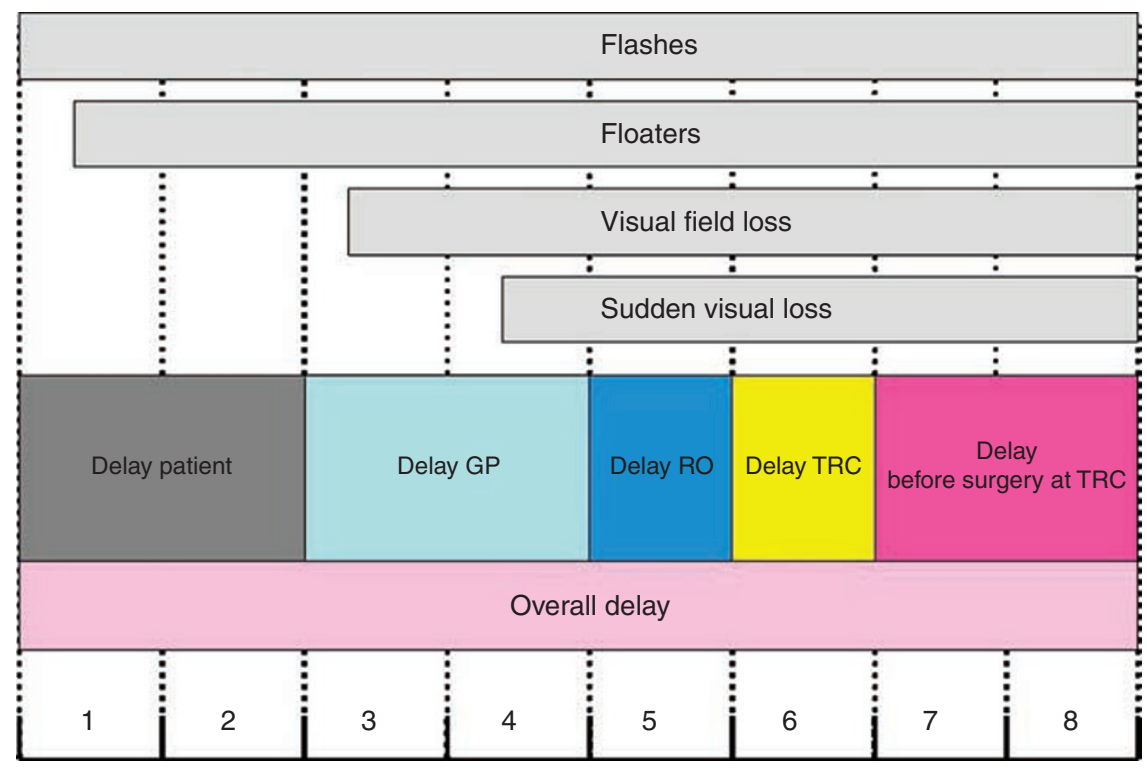

Time schedule (in days)

Figure 1 An example of how the different categories of delay for one patient were calculated. The first symptoms this patient had were flashes, followed a few days later by floaters, visual field loss and sudden visual loss. In this case, 'patient's delay' was 2 days, the 'general practitioner's (GP)' was also 2 days, the 'referring ophthalmologist's (RO)' delay' was 1 day and the 'delay at the tertiary referral center' (TRC) was also 1 day. The 'delay before surgery at the TRC' was 2 days. Thus, the cumulative or overall delay here was 8 days.

\section{Discussion}

The median overall delay between the first subjective symptoms and the time of surgery was 9 days. Almost $60 \%$ of this overall delay time was due to patient delay and GP delay. In addition, more than $50 \%$ of patients had a delay owing to the unawareness and/or unfamiliarity of the symptoms of PVD and/or RRD. For instance, patients explained that they did not consider the symptoms of flashes, floaters or visual field reduction as serious, so they did not haste to visit a physician. The mean patient delay was significantly lower in patients with a vitreous hemorrhage and in patients with a history of an RRD in the fellow eye. The acute loss in visual function (acuity and field) in patients with a vitreous hemorrhage is probably the reason that these patients seek immediate help. Patients who have been treated for an RRD of the fellow eye more easily recognize symptoms of an impending retinal detachment and thus seek contact at an earlier time point.

Our data were collected by interviewing the patients and using a questionnaire. To our experience, this 
Table 3 Patients (eye) characteristics

\begin{tabular}{|c|c|c|}
\hline Clinical variable & $\begin{array}{c}\text { Count } \\
(\mathrm{n}=186 \text { eyes })\end{array}$ & $\begin{array}{l}\text { Percentage } \\
(\%)\end{array}$ \\
\hline \multicolumn{3}{|l|}{ Gender } \\
\hline Male & 121 & 65.1 \\
\hline Female & 65 & 34.9 \\
\hline \multicolumn{3}{|l|}{ Eye } \\
\hline Right & 99 & 53.2 \\
\hline Left & 87 & 46.8 \\
\hline \multicolumn{3}{|l|}{ Quadrants involved } \\
\hline 1 & 57 & 30.5 \\
\hline 2 & 93 & 50.0 \\
\hline 3 & 22 & 11.8 \\
\hline 4 & 14 & 7.5 \\
\hline \multicolumn{3}{|l|}{$P V R$} \\
\hline None & 69 & 37.1 \\
\hline PVR A & 45 & 22.6 \\
\hline PVR B & 48 & 25.8 \\
\hline PVR C & 24 & 12.9 \\
\hline \multicolumn{3}{|l|}{ Macular involvement } \\
\hline Yes & 103 & 44.1 \\
\hline No & 82 & 55.4 \\
\hline Not known & 1 & 0.5 \\
\hline \multicolumn{3}{|l|}{ Retinal tear } \\
\hline Horse shoe & 96 & 51.6 \\
\hline Hole & 47 & 25.3 \\
\hline Ora dialysis & 4 & 2.2 \\
\hline Tear & 10 & 5.4 \\
\hline Missing & 29 & 15.6 \\
\hline \multicolumn{3}{|l|}{$\begin{array}{l}\text { Cumulative size of the retinal } \\
\text { tear in disc diameters }\end{array}$} \\
\hline 1 & 106 & 57.0 \\
\hline 2 & 33 & 17.7 \\
\hline 3 & 10 & 5.4 \\
\hline$<3$ & 5 & 2.7 \\
\hline Missing & 29 & 15.6 \\
\hline \multicolumn{3}{|l|}{ Pseudophakic eye } \\
\hline Yes & 69 & 37.1 \\
\hline No & 117 & 62.9 \\
\hline \multicolumn{3}{|l|}{ Fellow eye $R D$} \\
\hline Yes & 15 & 8.1 \\
\hline No & 171 & 91.9 \\
\hline \multicolumn{3}{|l|}{ Myopia of $>6$ diopters } \\
\hline Yes & 33 & 17.7 \\
\hline No & 151 & 81.2 \\
\hline Unknown & 2 & 1.1 \\
\hline \multicolumn{3}{|l|}{ Type of surgery } \\
\hline Scleral buckle & 138 & 74.2 \\
\hline Pars plana vitrectomy & 48 & 25.8 \\
\hline
\end{tabular}

$\mathrm{PVR}=$ proliferative vitreoretinopathy; $\mathrm{RD}=$ retinal detachment. method results in more accurate information than when a questionnaire is used without interviewing the patient. In the study of Quinn et al (United Kingdom), ${ }^{11}$ the referral route of patients with an RRD from primary-care providers to a tertiary care ophthalmic unit was also evaluated by means of interviews. They reported that more than $50 \%$ of patients had a significant delay owing to ignorance, a percentage that is comparable with our findings. They found that the majority of referred patients with RRD were from optometrists and GPs, accounting for nearly one-third of the referrals each. ${ }^{11}$ In contrast, in The Netherlands, $86 \%$ of patients first visit a GP. In our study, in $10 \%$ of cases $(n=20)$, the GP's made an incorrect diagnosis (see Table 4 ), resulting in a median GP delay of $0 \pm 20$ days.

Although the median patient-related delay was 4 days, the median GP and RO delay was 0 days. We excluded patients without abnormalities at first presentation to the retinal surgeon in a patient presenting with only a symptomatic PVD. In this case, a routine re-examination was scheduled within 6 weeks. The reason for exclusion was that their symptoms should be classified as symptoms of PVD or retinal breaks, and not of RRD. The patient may have developed an RRD prior to this scheduled visit, and found no reasons to consult the RO earlier. van Overdam et $a l^{12,13}$ found that $5 \%$ of patients developed a new retinal tear after the initial examination. In this study, $3 \%(n=6)$ of patients (two from the RO and four from our center) developed an RRD after the initial examination when only a PVD, without a retinal tear, was diagnosed. A total of six patients (four from the RO and two from our center) were also excluded who first received photocoagulation and later developed an RRD for the same reason.

Inclusion of these patients would have resulted in a relatively high $\mathrm{RO}$ delay time, a finding that would have biased the delay of the RO. Other forms of symptomatic PVDs that were also excluded are cases who present with a vitreous hemorrhage, in which successive ultrasonographies were performed by the $\mathrm{RO}$ or at the TRC, and who developed an RRD after a few days of follow-up.

PVD is a common age-related degeneration ${ }^{14,15}$ in which patients experience light flashes and/or floaters. ${ }^{16}$ These symptoms are specific for a PVD, although not all patients experience them. A study by Hikichi and Trempe ${ }^{16}$ showed a sensitivity of $89 \%$ and a specificity of $25 \%$ for floaters and flashes. This confirms the statement by Sebag ${ }^{17}$ that 'posterior vitreous detachment is perhaps the least accurate diagnosis entertained by ophthalmologists on a daily basis.' In addition, these findings confirm our results that there was no significant difference in delay between patients with or without flashes either in patients with or without floaters. Nevertheless, PVD is associated with an 
Table 4 Reasons for delay

\begin{tabular}{|c|c|c|c|c|c|}
\hline Categories of delay & Cause related to & $\begin{array}{l}\text { Number } \\
n(\%)\end{array}$ & $\begin{array}{l}\text { Median } \pm S D \\
\text { days }\end{array}$ & $\begin{array}{l}\text { Mean } \\
\text { delay }\end{array}$ & $\begin{array}{l}\text { Minimum- } \\
\text { maximum }\end{array}$ \\
\hline \multirow[t]{7}{*}{ Patient delay $(n=186)$} & No delay & $24(13)$ & 0 & 0 & 0 \\
\hline & 'Thought nothing serious' & $104(56)$ & $6 \pm 31$ & 17 & $1-230$ \\
\hline & Wait until next working day & $34(18)$ & $1 \pm 4$ & 3 & $1-20$ \\
\hline & Symptoms started on holidays & $6(3)$ & $7 \pm 1$ & 6 & $5-8$ \\
\hline & Wait for appointment & $6(3)$ & $6 \pm 4$ & 6 & $1-11$ \\
\hline & Other & $11(6)$ & $7 \pm 17$ & 15 & $2-50$ \\
\hline & Total & $186(100)$ & $4 \pm 25$ & 12 & $0-230$ \\
\hline \multirow[t]{5}{*}{ GP delay $(n=119)$} & No delay & $78(66)$ & 0 & 0 & 0 \\
\hline & Appointment first available place & $18(15)$ & $1 \pm 2$ & 1 & $1-7$ \\
\hline & Incorrect diagnosis & $20(17)$ & $14 \pm 42$ & 30 & $1-173$ \\
\hline & Other & $3(3)$ & $1 \pm 1$ & 1 & $1-2$ \\
\hline & Total & $119(100)$ & $0 \pm 20$ & 5 & $0-173$ \\
\hline \multirow[t]{7}{*}{ RO delay $(n=127)$} & No delay & $73(57)$ & 0 & 0 & 0 \\
\hline & Next day & $16(13)$ & 1 & 1 & 1 \\
\hline & GP referred without urgency & $17(13)$ & $4 \pm 12$ & 9 & $2-45$ \\
\hline & $\begin{array}{l}\text { First other treatment or additional diagnostic } \\
\text { procedure }^{\text {a }}\end{array}$ & $9(7)$ & $21 \pm 56$ & 52 & $8-180$ \\
\hline & $\begin{array}{l}\text { History with ophthalmologist, makes own } \\
\text { appointment }\end{array}$ & $6(5)$ & $15 \pm 12$ & 18 & $7-35$ \\
\hline & Patient was not able to come earlier & $7(6)$ & $4 \pm 11$ & 9 & $1-30$ \\
\hline & Total & $127(100)$ & $0 \pm 20$ & 6 & $0-180$ \\
\hline \multirow[t]{6}{*}{ Delay at our TRC $(n=186)$} & No delay & $145(78)$ & 0 & 0 & 0 \\
\hline & Appointment next day & $18(10)$ & 1 & 1 & 1 \\
\hline & Not referred as urgent & $12(6)$ & $1 \pm 15$ & 7 & $1-53$ \\
\hline & $\begin{array}{l}\text { First other treatment or additional diagnostic } \\
\text { procedure }^{\text {a }}\end{array}$ & $1(1)$ & 2 & 2 & 2 \\
\hline & Other & $10(5)$ & $3 \pm 3$ & 4 & $1-10$ \\
\hline & Total & $186(100)$ & $0 \pm 4$ & 1 & $0-53$ \\
\hline \multirow[t]{7}{*}{ Delay before surgery at TRC $(n=198)$} & No delay & $5(3)$ & 0 & 0 & 0 \\
\hline & Next scheduled day & $83(45)$ & $1 \pm 0$ & 1 & 1 \\
\hline & Over weekend & $26(14)$ & $2 \pm 1$ & 2 & $1-4$ \\
\hline & Scheduled within.......days & $36(20)$ & $7 \pm 6$ & 8 & $1-33$ \\
\hline & Emergency surgery not possible at that day & $25(13)$ & $2 \pm 1$ & 2 & $1-3$ \\
\hline & Other & $11(6)$ & $2 \pm 7$ & 7 & $2-20$ \\
\hline & Total & $186(101)$ & $1 \pm 4$ & 3 & $0-33$ \\
\hline
\end{tabular}

$\mathrm{GP}=$ general practitioner; $\mathrm{RO}=$ referring ophthalmologist; $\mathrm{TRC}=$ tertiary referral center.

For explanation and definitions of categories of delay see Table 1.

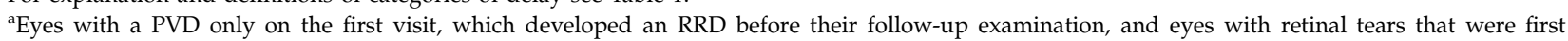
photocoagulated, but later developed an RD.

boperation room was not available or patients were unsuitable for surgery under local and/or general anesthesia.

increased risk for the development of retinal tears. ${ }^{12}$ Retinal tears have been reported in $7.3-14 \%$ of patients with a PVD. ${ }^{6}$ Although an RRD may be present or may develop after a PVD, subjective flashes and/or floaters can be absent. Considering that in The Netherlands, many RRD patients initially present at their GP's office, it is important that GP's are familiar with the complexity and variations of symptoms associated with an RRD and have adequate knowledge concerning the implications of these symptoms.

In this study, we found an extraordinary male-tofemale ratio of 134 males to 71 females. The pseudophakic male-to-female ratio was $51: 18$ (3:1), which was also shown in a study by Sheu et al ${ }^{18}$ who found a cumulative 6-year pseudophakic RRD rates of $1.90 \%$ in the male subgroup and $0.56 \%$ in the female subgroup at the end of the follow-up period. ${ }^{18}$

\section{Conclusion}

In summary, the median overall delay between the first subjective symptoms and the time of surgery was 10 days. Almost $60 \%$ of this overall delay time was due to patient delay and GP delay. More than $50 \%$ of patients 
Table 5 Delay in days of RD patients with or without a concomitant vitreous hemorrhage

\begin{tabular}{lcc}
\hline Categories of delay & $\begin{array}{c}\text { With vitreous hemorrhage }(n=7) \\
\text { Median } \pm S D \text { (range) days }\end{array}$ & $\begin{array}{c}\text { Without vitreous hemorrhage }(n=179) \\
\text { Median } \pm \text { SD (range) days }\end{array}$ \\
\hline Patient delay $^{\mathrm{a}}$ & $1 \pm 1.1(0-3)$ & $4.0 \pm 24.9(0-230)$ \\
GP delay & $0.0 \pm 0.4(0-1)$ & $0 \pm 20.6(0-173)$ \\
RO delay & $0.5 \pm 1.9(0-4)$ & $0.0 \pm 20.5(0-180)$ \\
Delay at TRC & $0.0 \pm 0.4(0-1)$ & $0.0 \pm 4.3(0-53)$ \\
Delay before surgery at TRC & $2.0 \pm 7.8(1-20)$ & $1.0 \pm 4.0(0-33)$ \\
Overall delay & $3 \pm 8.9(3-22)$ & $10 \pm 34.9(1-231)$
\end{tabular}

$\mathrm{GP}=$ general practitioner; $\mathrm{RO}=$ referring ophthalmologist; $\mathrm{TRC}=$ tertiary referral center.

For explanation and definitions of categories of delay see Table 2.

a $P<0.05$ for patients' delay between RD patients with $(n=7)$ and without $(n=179)$ a concomitant vitreous hemorrhage.

had a delay owing to unawareness and/or unfamiliarity with the symptoms of an RRD. Patient and GP education may therefore be a primary goal to improve functional outcome after RRD surgery. A complete funduscopic examination, including three-mirror contact lens examination, should be performed by the ophthalmologist in every symptomatic patient, and re-examinations within 6 weeks should be scheduled for these patients. Patients should also be well instructed to return earlier when symptoms worsen. Patients should be made more aware of the meaning of symptoms, such as flashes, floaters and visual field loss, and advised to contact an ophthalmologist more promptly. Education could be imparted to patients who are at risk for RRD (eg, in cases of myopia) when they visit the ophthalmologist for any other reason, and by using brochures. Also, the GP should be aware of the different symptoms that can cause a PVD and/or RRD. For instance, the GP could be educated by an article in a national or GP magazine.

\section{Disclosure}

The authors state no conflict of interest.

\section{References}

1 Heimann H, Hellmich M, Bornfeld N, Bartz-Schmidt KU, Hilgers RD, Foerster MH. Scleral buckling vs primary vitrectomy in rhegmatogenous retinal detachment (SPR Study): design issues and implications. SPR Study report no. 1. Graefes Arch Clin Exp Ophthalmol 2001; 239: 567-574.

2 Sasaki K, Ideta H, Yonemoto J, Tanaka S, Hirose A, Oka C. Epidemiologic characteristics of rhegmatogenous retinal detachment in Kumamoto, Japan. Graefes Arch Clin Exp Ophthalmol 1995; 233: 772-776.

3 La Heij EC, Derhaag PF, Hendrikse F. Results of scleral buckling operations in primary rhegmatogenous retinal detachment. Doc Ophthalmol 2000; 100: 17-25.

4 Diederen RM, La Heij EC, Kessels AG, Goezinne F, Liem AT, Hendrikse F. Scleral buckling surgery after macula-off retinal detachment: worse visual outcome after more than 6 days. Ophthalmology 2007; 114: 705-709.

5 Ross WH, Kozy DW. Visual recovery in macula-off rhegmatogenous retinal detachments. Ophthalmology 1998; 105: 2149-2153.

6 Hassan TS, Sarrafizadeh R, Ruby AJ, Garretson BR, Kuczynski B, Williams GA. The effect of duration of macular detachment on results after the scleral buckle repair of primary, macula-off retinal detachments. Ophthalmology 2002; 109: 146-152.

7 Sharma T, Challa JK, Ravishankar KV, Murugesan R. Scleral buckling for retinal detachment. Predictors for anatomic failure. Retina 1994; 14: 338-343.

8 Salicone A, Smiddy WE, Venkatraman A, Feuer W. Visual recovery after scleral buckling procedure for retinal detachment. Ophthalmology 2006; 113: 1734-1742.

9 Liem AT, Keunen JE, van Meel GJ, van Norren D. Serial foveal densitometry and visual function after retinal detachment surgery with macular involvement. Ophthalmology 1994; 101: 1945-1952.

10 The Retina Society Terminology Committee. The classification of retinal detachment with proliferative vitreoretinopathy. Ophthalmology 1983; 90: 121-125.

11 Quinn SM, Qureshi F, Charles SJ. Assessment of delays in presentation of patients with retinal detachment to a tertiary referral centre. Ophthalmic Physiol Opt 2004; 24: 100-105.

12 van Overdam KA, Bettink-Remeijer MW, Mulder PG, van Meurs JC. Symptoms predictive for the later development of retinal breaks. Arch Ophthalmol 2001; 119: 1483-1486.

13 van Overdam KA, Bettink-Remeijer MW, Klaver CC, Mulder PG, Moll AC, van Meurs JC. Symptoms and findings predictive for the development of new retinal breaks. Arch Ophthalmol 2005; 123: 479-484.

14 Yonemoto J, Ideta H, Sasaki K, Tanaka S, Hirose A, Oka C. The age of onset of posterior vitreous detachment. Graefes Arch Clin Exp Ophthalmol 1994; 232: 67-70.

15 Byer NE. Natural history of posterior vitreous detachment with early management as the premier line of defense against retinal detachment. Ophthalmology 1994; 101: 1503-1513; discussion 13-14.

16 Hikichi T, Trempe CL. Relationship between floaters, light flashes, or both, and complications of posterior vitreous detachment. Am J Ophthalmol 1994; 117: 593-598.

17 Sebag J. Imaging vitreous. Eye 2002; 16: 429.

18 Sheu SJ, Ger LP, Chen JF. Male sex as a risk factor for pseudophakic retinal detachment after cataract extraction in Taiwanese adults. Ophthalmology 2007; 114: 1898-1903. 